\title{
Suppression of O-Linked Glycosylation of the SARS-CoV-2 Spike by Quaternary Structural Restraints
}

\author{
Charles F. S. Eldrid, ${ }^{\#}$ Joel D. Allen, ${ }^{\#}$ Maddy L. Newby, and Max Crispin*
}

Cite This: Anal. Chem. 2021, 93, 14392-14400

Read Online

ABSTRACT: Understanding the glycosylation of the envelope spike (S) protein of SARS-CoV-2 is important in defining the antigenic surface of this key viral target. However, the underlying protein architecture may significantly influence glycan occupancy and processing. There is, therefore, potential for different recombinant fragments of $S$ protein to display divergent glycosylation. Here, we show that the receptor binding domain (RBD), when expressed as a monomer, exhibits O-linked glycosylation, which is not recapitulated in the nativelike soluble trimeric protein. We unambiguously assign O-linked glycosylation by homogenizing N-linked glycosylation using the enzymatic inhibitor, kifunensine, and then analyzing the resulting structures by electron-transfer higher-energy collision dissociation

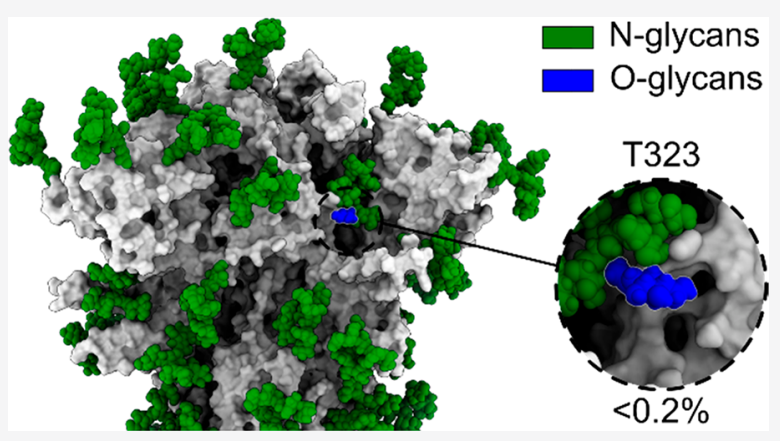
(EThcD) in an Orbitrap Eclipse Tribrid instrument. In the native-like trimer, we observe a single unambiguous O-linked glycan at T323, which displays very low occupancy. In contrast, several sites of O-linked glycosylation can be identified when RBD is expressed as a monomer, with T323 being almost completely occupied. We ascribe this effect to the relaxation of steric restraints arising from quaternary protein architecture. Our analytical approach has also highlighted that fragmentation ions arising from trace levels of truncated $\mathrm{N}$-linked glycans can be misassigned as proximal putative O-linked glycan structures, particularly where a paucity of diagnostic fragments were obtained. Overall, we show that in matched expression systems the quaternary protein architecture limits O-linked glycosylation of the spike protein.

Cevere acute respiratory syndrome coronavirus 2 (SARS$\checkmark \mathrm{CoV}-2$ ) is the recently emerged zoonotic agent responsible for the COVID-19 pandemic. ${ }^{1-3}$ SARS-CoV-2 is a member of the Betacoronavirus genera of enveloped RNA viruses, which also includes SARS-CoV-1 and Middle Eastern respiratory syndrome-coronavirus (MERS-CoV). ${ }^{4,5}$ SARS-CoV-2 tissue tropism is defined by the spike $(S)$ protein. ${ }^{6}$ The $S$ protein is formed of a trimer of heterodimers (Figure 1A,B) that controls cellular fusion with host cells through the binding of angiotensin-converting enzyme 2 (ACE2) cellular receptors. $^{7-9}$ The $S$ protein is the major surface transmembrane protein and is the principle antigenic target in current vaccine strategies, ${ }^{10,11}$ and a key component of serological tests. ${ }^{12,13}$ It is therefore important that we understand the immunogenic surface of the $S$ protein.

The ectodomains of $S$ proteins of coronaviruses have been shown to be modified with glycans, which can facilitate hostcell binding. ${ }^{14-20}$ In addition, glycans can obfuscate immunological recognition of the protein surface through glycan shielding, ${ }^{21-23}$ although not to the same extent as human immunodeficiency virus (HIV). ${ }^{21,24,25}$

Glycans are carbohydrates added as a post-translational modification, in a process called glycosylation, during glycoprotein secretion. ${ }^{26}$ Viral spike protein glycosylation occurs via two main mechanisms: the addition of glycans to asparagine residues, termed $\mathrm{N}$-linked glycosylation, or $\mathrm{O}$ linked glycosylation, which typically occurs at serine or threonine residues. ${ }^{27} \mathrm{~N}$-linked glycans are added to Asn residues within the $\mathrm{N}$-linked sequon, $\mathrm{N}-\mathrm{X}-\mathrm{S} / \mathrm{T}$, and so potential N-linked glycosylation sites (PNGS) can be identified from a primary protein sequence. In contrast, Olinked glycans are present in high levels on mucin domains and display a bias toward disordered Ser-, Thr-, Pro-rich (STP) domains, but do not have a conserved sequon. ${ }^{28}$ This makes O-linked glycans more difficult to study because of their lack of predictability.

The N-linked glycosylation of SARS-CoV-2 S protein has been previously studied, showing high occupancy of 22 PNGS; ${ }^{29-31}$ however, there are differing reports about the level of occupancy, and localization of, O-linked glycans. ${ }^{25,32-37}$ In this study we use kifunensine, which inhibits $\alpha 1,2$-mannosidases following the Calnexin/Calreticulin folding

Received: April 26, 2021

Published: October 20, 2021 


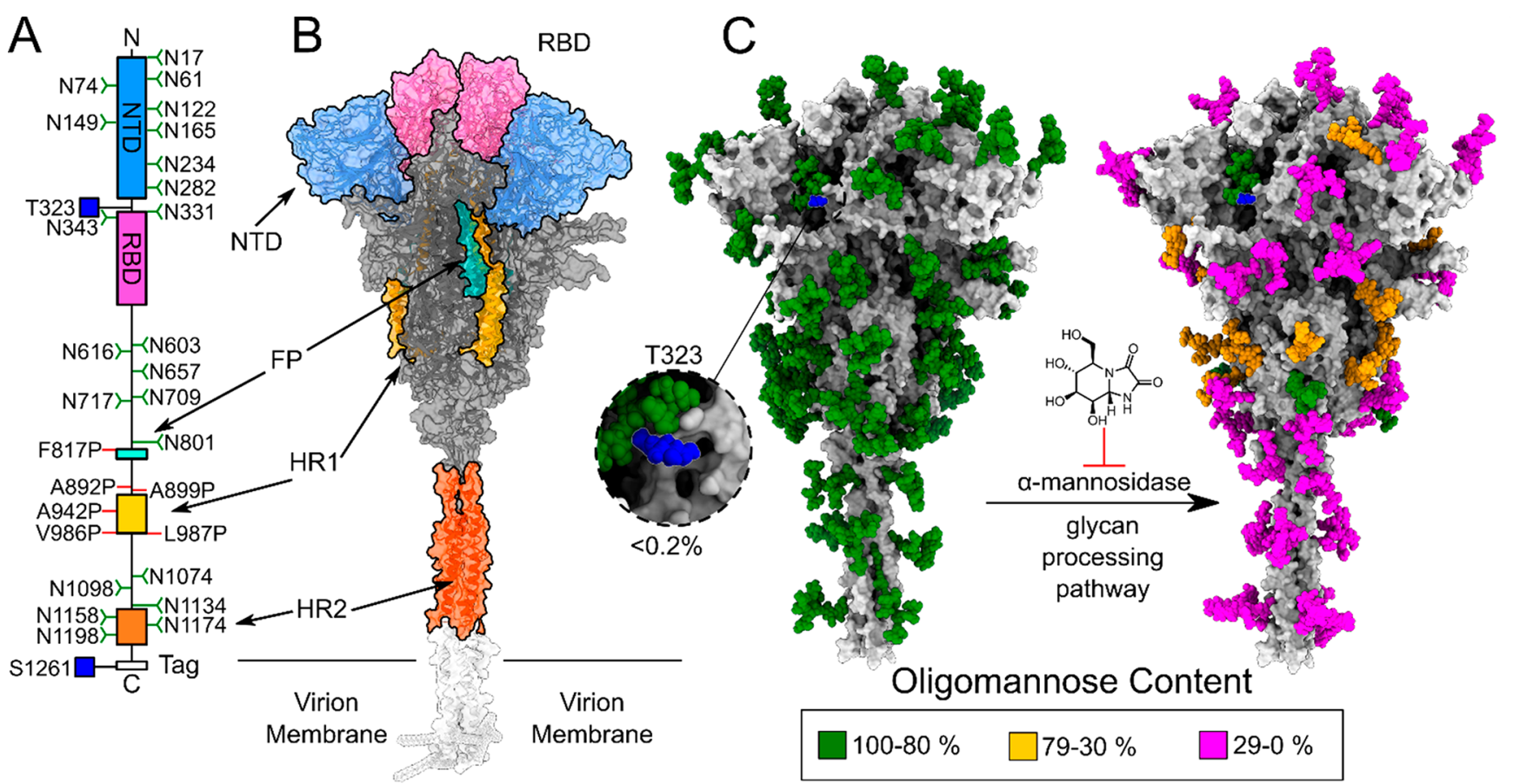

Figure 1. Overview of structure and glycosylation of the S-protein construct, using the full-length S-protein model presented in Allen et al., ${ }^{31}$ with the N-terminal domain (NTD) in blue, receptor binding domain (RBD) in pink, the fusion peptide (FP) in cyan, the heptapeptide repeat sequence 1 (HR1) in yellow, and the heptapeptide repeat sequence 2 (HR2) in orange, with oligomannose N-linked glycans in green and the O-linked glycans in blue. (A) Primary structure of the S protein with N- and O-linked glycans and stabilizing protein mutations labeled; (B) full structure of the spike protein, with the NTD, RBD, FP, HR1, and HR2 colored according to the primary structure; (C) spike protein construct with both high mannose and dominant glycans as presented by Watanabe, Allen and co-workers, ${ }^{25}$ with the $\mathrm{Man}_{9} \mathrm{GlcNAc}_{2}$ glycans shown in green, hybrid glycans shown in yellow, and complex glycans shown in magenta and O-linked glycans in blue. Inset: the close-up of the T323 O-glycan on the structure of the high mannose glycoform with the percentage occupancy.

cycle, ${ }^{38}$ to simplify $\mathrm{N}$-linked glycosylation prior to studying the SARS-CoV-2 $S$ protein. The inhibition by kifunensine induces $\mathrm{N}$-linked glycan homogeneity, resulting in the predominant display of $\mathrm{Man}_{9} \mathrm{GlcNAc}_{2}$ glycans. Kifunensine has been previously used to study heavily glycosylated glycoproteins in both a crystallographic ${ }^{39}$ and intact mass spectrometry setting. ${ }^{40}$ Here, we use kifunensine to simplify bottom-up Nlinked fragmentation spectra, lowering the chance of falsepositive O-linked glycan identification in several ways. ${ }^{40}$ Firstly, it simplifies the N-linked glycans while ostensibly leaving the O-linked glycans untouched, preventing possible misassignment of $\mathrm{N}$-linked structures as complex O-glycans, that is, as a complex extended core structure. Secondly, it facilitates initial peptide searches with both $\mathrm{N}$ - and O-linked glycan comodifications. Third, it accelerates the manual verification required during joint $\mathrm{N}$ - and O-linked glycan searches, allowing better discrimination of misassigned $\mathrm{N}$ glycans.

We study two different forms of prefusion stabilized $S$ protein, the $2 \mathrm{P}^{41,42}$ and HexaPro ${ }^{43}$ constructs, expressed in the presence of kifunensine, using a bottom-up mass spectrometry (MS) approach with electron-transfer higher-energy collision dissociation (EThcD), ${ }^{4-46}$ to study O-linked glycosylation. EThcD offers a softer fragmentation approach than pure higher-energy collision dissociation (HCD), preventing dissociation of the glycan from the peptide, which is beneficial for O-linked glycan analysis as there is no conserved sequon. ${ }^{44-46}$ During data analysis a search of up to three glycan comodifications per peptide, on either $\mathrm{N}$ - or O-linked glycan sites, was performed, where the sites can be easily verified or rejected if non-oligomannose-type glycans were observed at the $\mathrm{N}$-linked glycan sites, or if there was incomplete fragmentation between $\mathrm{N}$ - and O-linked glycan sites. Using this approach, we observe a single unambiguous $\mathrm{O}$ linked glycan on the S-protein ectodomains at site T323 in the receptor binding domain (RBD), with low occupancy, with our $\mathrm{N}$-linked glycosylation patterns matching previously published data. We considered a glycosylation site unambiguous if it was identified in multiple analytical repeats and had appropriate backbone fragmentation between the O-linked glycan site and any other possible glycan sites. In comparison, monomeric RBD displayed very high occupancy of the T323 site, with greater glycan processing evident. We hypothesize that the higher occupancy and processing of this site is due to a lack of steric hindrance from the quaternary structure of the full trimeric spike. We also explored the impact of kifunensine on O-glycan occupancy and composition on monomeric RBD, observing consistent occupancy between O-linked glycan sites; however, unexpectedly, kifunensine appeared to increase sialylation of O-linked glycans. We find that the use of kifunensine treatment helps reduce misassignments of glycan attachment sites derived from nearby $\mathrm{N}$-glycans as $\mathrm{O}$ glycosylation sites because of poor fragmentation. Elucidation of the pattern of $\mathrm{N}$ - and O-linked glycan occupancy are important parameters in defining the antigenic surface of viral glycoproteins.

\section{METHODS}

Expression and Purification. HEK293F cells were cultured in Freestyle 293 Expression Medium (Fisher Scientific) and maintained at a density of $0.2 \times 10^{6}$ cells $/ \mathrm{mL}$ 
at $37{ }^{\circ} \mathrm{C}, 8 \% \mathrm{CO}_{2}$, and $125 \mathrm{rpm}$ shaking. $293 \mathrm{~F}$ cells were transiently transfected with plasmid containing SARS-CoV-2 S (GenBank ID: MN908947) to generate two forms of soluble SARS-CoV-2 prefusion ectodomain, one with stabilizing proline mutations at residues 986 and $987(2 \mathrm{P})^{41,42}$ and another with additional mutations at 817, 892, 899, and 942 (HexaPro). ${ }^{43}$ Both proteins contained a C-terminal octahistadine and Strep-tag II. Prior to transfection, two solutions of $10 \mathrm{~mL}$ of Opti-MEM (Fisher Scientific) medium were prepared. SARS-CoV-2 $S$ was added to the first solution to give a final concentration of $310 \mu \mathrm{g} / \mathrm{L}$. To the other solution, $1 \mathrm{mg} /$ $\mathrm{mL}(\mathrm{pH}$ 7) polyethylenimine (PEI) max reagent was added to generate a ratio of 3:1 PEI max/plasmid DNA. Both solutions were combined and incubated for $30 \mathrm{~min}$ at room temperature. Cells were transfected at a density of $1 \times 10^{6}$ cells $/ \mathrm{mL}$ and incubated for 7 days at $37{ }^{\circ} \mathrm{C}, 8 \% \mathrm{CO}_{2}$, and $125 \mathrm{rpm}$ shaking. At the time of transfection, $20 \mu \mathrm{M}$ kifunensine was added to elicit oligomannose-type glycans.

Cells were centrifuged at $3041 \mathrm{~g}$ for $30 \mathrm{~min}$ at $4{ }^{\circ} \mathrm{C}$, and supernatant was applied to a $500 \mathrm{~mL}$ Stericup-HV sterile vacuum filtration system (Merck) with a pore size of $22 \mu \mathrm{m}$. Purification of SARS-CoV-2 spike protein was undertaken

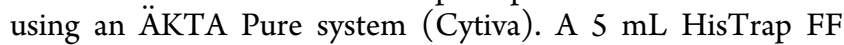
column (Cytiva) charged with $\mathrm{Ni}$ (II) was equilibrated using 10 column volumes $(\mathrm{CV})$ of washing buffer $\left(50 \mathrm{mM} \mathrm{Na}_{2} \mathrm{PO}_{4}, 300\right.$ $\mathrm{mM} \mathrm{NaCl})$ at $\mathrm{pH}$ 7. Supernatant was loaded onto the column at a flow rate of $2 \mathrm{~mL} / \mathrm{min}$ and washed with $10 \mathrm{CV}$ of washing buffer containing $50 \mathrm{mM}$ imidazole. Protein was eluted in 3 $\mathrm{CV}$ of elution buffer ( $300 \mathrm{mM}$ imidazole in washing buffer) and buffer exchanged to phosphate buffered saline (PBS) using a Vivaspin column (MWCO $100 \mathrm{kDa}$ ) (Cytiva).

The nickel purified eluate was concentrated to $1 \mathrm{~mL}$ in PBS and injected into a Superdex 200 pg 16/600 column (Cytiva) to isolate trimeric spike protein using size exclusion chromatography (SEC). The column was washed with PBS at $1 \mathrm{~mL} / \mathrm{min}$ for $2 \mathrm{~h}$, and fractions corresponding to the correct peak on the size exclusion chromatogram were collected and concentrated to $1 \mathrm{~mL}$ as above.

Sample Preparation. Three aliquots of each sample were denatured for $1 \mathrm{~h}$ in $50 \mathrm{mM}$ Tris/ $\mathrm{HCl}(\mathrm{pH} \mathrm{8.0)}$ containing 6 $\mathrm{M}$ urea and $5 \mathrm{mM}$ dithiothreitol (DTT). Next, spike proteins were reduced and alkylated by adding $20 \mathrm{mM}$ iodoacetamide (IAA) and incubated for $1 \mathrm{~h}$ in the dark, followed by a $1 \mathrm{~h}$ incubation with $20 \mathrm{mM}$ DTT to eliminate residual IAA. The alkylated spike proteins were buffer-exchanged into $50 \mathrm{mM}$ Tris/ $\mathrm{HCl}(\mathrm{pH} 8.0)$ using Vivaspin columns ( $3 \mathrm{kDa})$, and two of the aliquots were digested separately overnight using trypsin, chymotrypsin (Mass Spectrometry grade, Promega), or alphalytic protease (Sigma-Aldrich) at a ratio of 1:30 (w/w). The next day, the peptides were dried and extracted using C18 Ziptip (MerckMilipore).

Mass Spectrometry. The peptides were dried again, resuspended in $0.1 \%$ formic acid, and analyzed by nanoLC-ESI MS with an Ultimate 3000 HPLC (Thermo Fisher Scientific) system coupled to an Orbitrap Eclipse mass spectrometer (Thermo Fisher Scientific) using electron-transfer high-energy collision dissociation (EThcD) fragmentation. Peptides were separated using an EasySpray PepMap RSLC C18 column (75 $\mu \mathrm{m} \times 75 \mathrm{~cm}$ ). A trapping column (PepMap $100 \mathrm{C} 183 \mu \mathrm{m} \times$ $75 \mu \mathrm{m} \times 2 \mathrm{~cm}$ ) was used in-line with the LC prior to separation with the analytical column. The LC conditions were as follows: $280 \mathrm{~min}$ linear gradient consisting of $4-32 \%$ acetonitrile in $0.1 \%$ formic acid over $260 \mathrm{~min}$ followed by 20 min of alternating $76 \%$ acetonitrile in $0.1 \%$ formic acid and $4 \%$ Acn in $0.1 \%$ formic acid, used to ensure all the sample had eluted from the column. The flow rate was set to $300 \mathrm{~nL} / \mathrm{min}$. The spray voltage was set to $2.7 \mathrm{kV}$, and the temperature of the heated capillary was set to $40{ }^{\circ} \mathrm{C}$. The ion-transfer tube temperature was set to $275^{\circ} \mathrm{C}$. The scan range was $375-1500$ $m / z$. EThcD reaction kinetics were determined with prior calibration using Pierce FlexMix with supplemental higher energy collision dissociation set to $15 \%$. Precursor and fragment detection were performed using an Orbitrap at a resolution $\mathrm{MS} 1=120000$ and $\mathrm{MS} 2=30000$. The AGC target for MS1 was set to standard and the injection time set to auto, which involves the system setting the two parameters to maximize sensitivity while maintaining cycle time. Full LC and MS methodology can be extracted from the appropriate raw file using XCalibur FreeStyle software or upon request (MassIVE MSV000087897).

Data Analysis. Glycopeptide fragmentation data were extracted from the raw file using Byos (Version 3.5; Protein Metrics Inc.) and filtered for a score above 100. The glycopeptide fragmentation data were evaluated manually for each glycopeptide; the peptide was scored as true positive when the correct a-, b-, c-, x-, y-, and z-fragment ions were observed along with oxonium ions corresponding to the glycan identified. The MS data were searched using the Protein Metrics 305 N-linked glycan library with sulfated glycans added manually. The relative amounts of each glycan at each site as well as the unoccupied proportion were determined by comparing the extracted chromatographic areas for different glycotypes with an identical peptide sequence. All charge states for a single glycopeptide were summed. The precursor mass tolerance was set at 4 and $10 \mathrm{ppm}$ for fragments. A $1 \%$ false discovery rate (FDR) was applied. The relative amounts of each glycan at each site as well as the unoccupied proportion were determined by comparing the extracted ion chromatographic areas (XIC) for different glycopeptides with an identical peptide sequence. Glycans were categorized according to the composition detected. The O-linked glycan occupancy was calculated for each glycopeptide via XIC, and the occupancy was averaged across different glycopeptides across analytical repeats. For N-linked glycosylation, highintensity glycopeptides (XIC > e10) were selected from analytical repeats to confirm successful kifunensine treatment.

\section{RESULTS AND DISCUSSION}

High HexaPro N-Linked Glycan Occupancy. Previous publications have identified $22 \mathrm{~N}$-linked glycosylation sites on the S-protein ectodomains. ${ }^{25,33,34}$ We were able to unambiguously determine the glycosylation state of 21 of the $22 \mathrm{~N}$ linked glycan sites, but did not see signal for the N17 glycan, due to poor $\mathrm{N}$-terminal peptide coverage. With expression in the presence of kifunensine ('kifunensine treatment', KT), a majority of oligomannose-type glycans were observed on all sites (Figure 2A) compared to previous publications, which show Spike N-linked glycans consist predominantly of complex-type glycans. ${ }^{25}$ Over $95 \%$ of all sites were observed as being occupied by oligomannose-type glycans, confirming the efficacy of kifunensine (Figure 2B).

Only one site of O-linked glycosylation could be unambiguously assigned to the S-protein ectodomain: T323. Low occupancy of the site with a HexNAc(1) (approximately $0.02 \%$ occupancy) was observed with fragmentation of either side of the T323 (Figure S2). This single O-glycan site was 


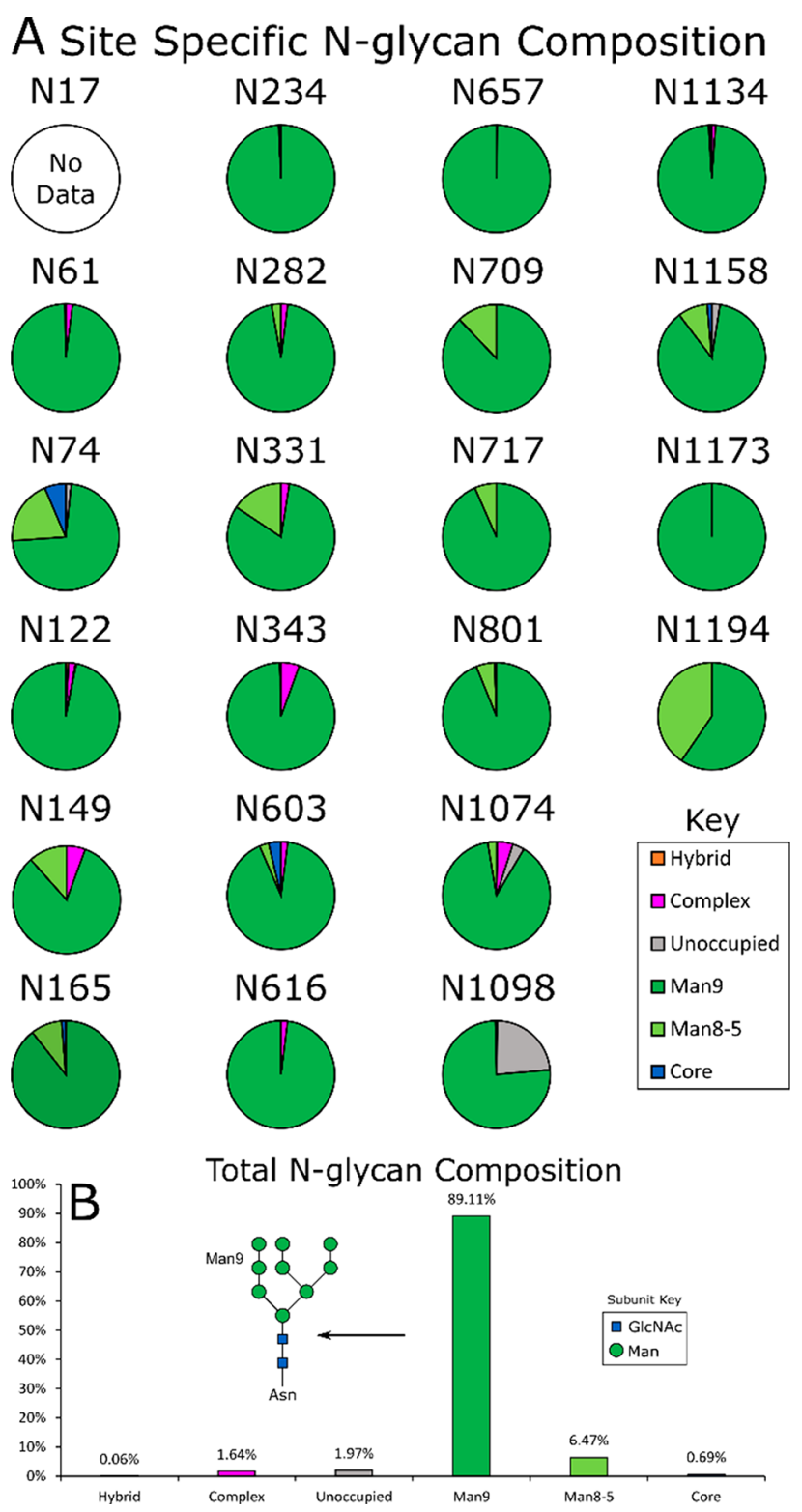

Figure 2. The N-linked glycan composition of HexaPro expressed in the presence of kifunensine: oligomannose-type (green), hybrid-type (orange), complex-type (magenta), unoccupied (gray), and core (blue). (A) Pie charts displaying glycan composition by N-linked glycan site, with a breakdown between $\mathrm{Man}_{9} \mathrm{GlcNAc}_{2}$ (Man9; dark green) and other oligomannose-type glycans: $\mathrm{Man}_{8}-\mathrm{Man}_{5} \mathrm{GlcNAc}_{2}$ (Man8-5; light green). (B) N-linked glycan composition, averaged across all sites.

also observed by Watanabe et al., Zhao et al., and Shajahan et al., although at higher occupancy. ${ }^{25,33,47}$ The only other unambiguous site of O-linked glycosylation in the present study was a $S 1261$ present on the protein purification tag (approximately 6\% occupancy, Figure S2, Table S2).

In addition to this, we observed many ambiguous assignments of O-linked glycans during analysis. The majority of these assigned O-linked glycans contained only a single HexNAc within close proximity to previously identified $\mathrm{N}$ linked glycans. Further examination revealed that these sites were ambiguous assignments, where there were no assigned fragment ions between the $\mathrm{S} / \mathrm{T}$ and the nearby $\mathrm{N}$-glycan (Figure 3). Other modifications could be manually rejected for reasons such as incorrect monoisotopic precursor peak selection, missing isotope peaks, and lack of diagnostic ions.

Our data is in contrast to recent studies and preprints, suggesting a high number of assigned O-linked glycan sites in the vicinity of $\mathrm{N}$-sequons. ${ }^{32,35,48}$ A possible reason for these discrepancies could be that the use of PNGase F in these studies, used to remove $\mathrm{N}$-linked glycans, would not remove residual $\operatorname{HexNAc}(1)$ remaining from $\mathrm{N}$-linked glycan degradation. $^{49,50}$ Unambiguous assignment of an O-linked Hex$\mathrm{NAc}(1)$ in proximity to $\mathrm{N}$-glycan sequons requires a parallel search for $\mathrm{N}$-linked modifications and good fragmentation of the $\mathrm{N}$ sequon; otherwise, software pipelines will assign false $\mathrm{O}$ linked glycan sites (Figure 3).

Comparison to 2P Construct. As previous studies have used the 2P stabilized spike construct, which has four fewer proline substitutions compared to the HexaPro construct and exhibits lower expression levels in protein production, we compared glycosylation of HexaPro that of $2 \mathrm{P}^{41,42}$ We performed an identical O-linked glycan site search on KT 2P. We observed an O-linked HexNAc(1) on T323 at $0.23 \%$ occupancy, higher than that observed on HexaPro (Figure 4, Figure S3, Table 1, Table S2). This observation is consistent with the additional proline substitutions increasing the stability of the construct and suppressing the initiation of O-linked glycosylation. No unambiguous O-glycans other than those previously identified were observed.

Low-Confidence Ambiguous O-Linked Glycans. As previously stated, we considered a glycosylation site "unambiguous" if it was present on multiple peptides across analytical repeats, and there was sufficient fragmentation data to distinguish it from any other possible O-linked glycan sites. We observed several examples of O-linked glycan sites for which a single peptide was marked as a true positive, at low intensities, including T124, T478, T696/S698/S704 (there was not sufficient fragmentation to localize the O-linked glycan site), and S1175 (Figure S4). We include these ambiguous Olinked glycan sites for transparency; however, we do not have confidence in their validity.

High RBD O-Linked Glycan Occupancy. We explored $\mathrm{KT} \mathrm{RBD}$ as a comparison to both the HexaPro and $2 \mathrm{P}$ constructs, to highlight how the quaternary structure impacts the occupancy on T323. We observed the T323 glycosite at much higher occupancy in the RBD. The dominant glycan in this position is a disialylated core-I (Figure 5A), HexNAc(1)$\mathrm{Hex}(1) \mathrm{NeuAc}(2)$, representing $99 \%$ of total glycan compositions. We also observed unambiguous O-glycan on sites S469/ T470 and T523 at occupancies below 1\% (Figure 5B). The discrepancy between the occupancy on T323 between fulllength $S$ protein is likely due to the fact that T323 is located within a cleft on the full-length trimer, but is more accessible in the monomeric RBD (Figure 5E,F). This is supported by the fact that the $\mathrm{N} 234$ glycan (which is in close proximity to T323, Figure 5E) is dominated by oligomannose structures in wildtype (WT) $2 \mathrm{P}^{25}$, and molecular dynamics simulations suggest that this glycan has very low solvent accessibility. ${ }^{31,51}$ A similar effect is observable with T499 within HIV gp120. ${ }^{52}$

To assess whether kifunensine impacts the occupancy of $\mathrm{O}$ linked glycans, such as through steric hindrance of the glycosylation machinery by the artificial addition of oligomannose-type glycans, we performed a comparison of WT and KT SARS-CoV-2 RBD. We observe the same O-glycan sites (T323, S469/T470, and T523) with similar occupancies (Figure 5B). In comparison to those of $\mathrm{KT} \mathrm{RBD,} \mathrm{the}$ 

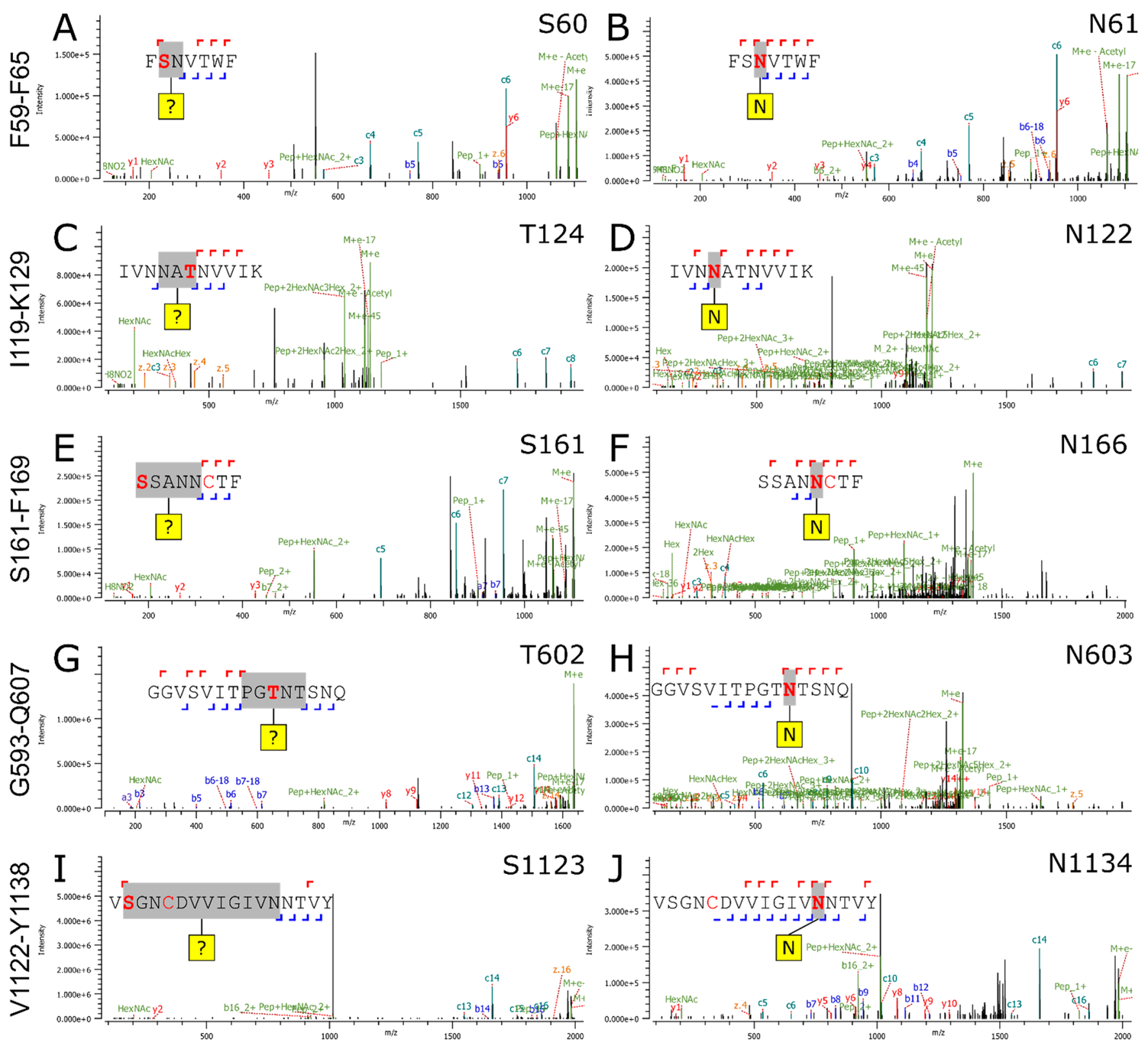

Figure 3. (A, C, E, G, I) Example fragmentation spectra of various ambiguous O-linked glycan assignments. (B, D, F, H, J) Corresponding assigned $\mathrm{N}$-glycan, with the glycosylation site and the annotated peptide fragments, with the corresponding assigned glycan site in bold.

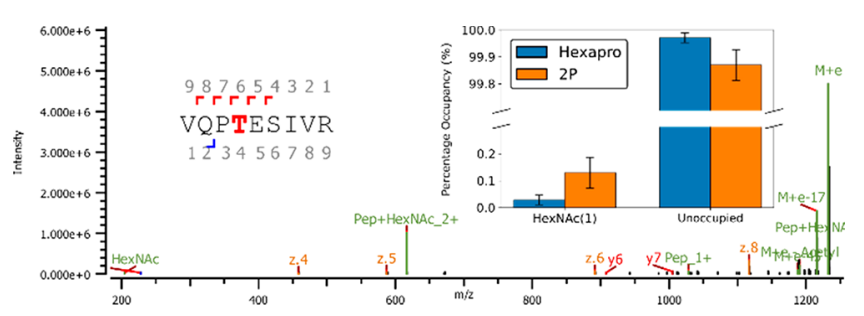

Figure 4. T323 O-glycan site: Example of unambiguous fragmentation spectra with inset: occupancy of T323 with $\operatorname{HexNAc}(1)$ in HexaPro (blue) and 2P (orange) constructs. For additional spectra see Figures S2 and S3.

dominant glycans at T323 are mono- and disialylated core-I structures, $\operatorname{HexNAc}(1) \operatorname{Hex}(1) \mathrm{NeuAc}(1)$ and $\operatorname{HexNAc}(1)$ $\operatorname{Hex}(1) \mathrm{NeuAc}(2)$ (Figure 5C,D), representing $80 \%$ of total glycan compositions (Figure 5A). Various other O-glycan structures were observed at low levels, with the total occupancy of the T323 site at approximately 97\%, comparable to that of KT RBD. Interestingly, we see a distinct shift from mono- to disialylation between WT and $\mathrm{KT} \mathrm{RBD}$, and a decrease in overall O-linked glycan complexity at this site (Figure 5A). We hypothesize that the use of kifunensine results in an increase in the overall substrate available for sialyltransferases as kifunensine prevents the sialylation of $\mathrm{N}$-linked glycosylation. In this model, the increase in the sialylation of O-linked glycans caps their further maturation, reducing complexity. ${ }^{53}$

\section{CONCLUSION}

We use kifunensine to simplify the N-linked glycome of the HexaPro and $2 \mathrm{P}$ constructs of the SARS-CoV-2 S protein, observing a single unambiguous O-glycan present on the ectodomain. We and others have previously reported T323 and S325 as O-linked glycosylation sites on the $2 \mathrm{P}$ construct; however, we now unambiguously assign $\mathrm{T} 323$ as the only 
Table 1. Unambiguously Identified O-Linked Glycans by Peptide and Full-Length Construct

\begin{tabular}{|c|c|c|c|c|c|c|c|}
\hline site & construct & sequence & glycans & score & XIC occupied & XIC unoccupied & occupancy \\
\hline T323 & HexaPro & R.VQPtESIVR.F & $\operatorname{HexNAc}(1)$ & 176.05 & $5.91 \times 10^{07}$ & $5.21 \times 10^{11}$ & $0.01 \%$ \\
\hline T323 & HexaPro & S.NFRVQPtESIV.R & $\operatorname{HexNAc}(1)$ & 191.31 & $1.42 \times 10^{08}$ & $3.00 \times 10^{11}$ & $0.05 \%$ \\
\hline T323 & HexaPro & R.VQPtESIVR.F & $\operatorname{HexNAc}(1)$ & 176.14 & $5.32 \times 10^{07}$ & $6.25 \times 10^{11}$ & $0.01 \%$ \\
\hline T323 & $2 \mathrm{P}$ & S.NFRVQPtESIV.R & $\operatorname{HexNAc}(1)$ & 170.59 & $3.22 \times 10^{08}$ & $6.77 \times 10^{10}$ & $0.47 \%$ \\
\hline T323 & $2 \mathrm{P}$ & F.RVQPtESIV.R & $\operatorname{HexNAc}(1)$ & 192.53 & $1.07 \times 10^{08}$ & $6.77 \times 10^{10}$ & $0.16 \%$ \\
\hline T323 & $2 \mathrm{P}$ & R.VQPtESIVR.F & $\operatorname{HexNAc}(1)$ & 197.33 & $5.36 \times 10^{08}$ & $3.01 \times 10^{11}$ & $0.18 \%$ \\
\hline T323 & $2 \mathrm{P}$ & F.RVQPtESIV.R & $\operatorname{HexNAc}(1)$ & 171.6 & $3.40 \times 10^{07}$ & $6.55 \times 10^{10}$ & $0.05 \%$ \\
\hline
\end{tabular}

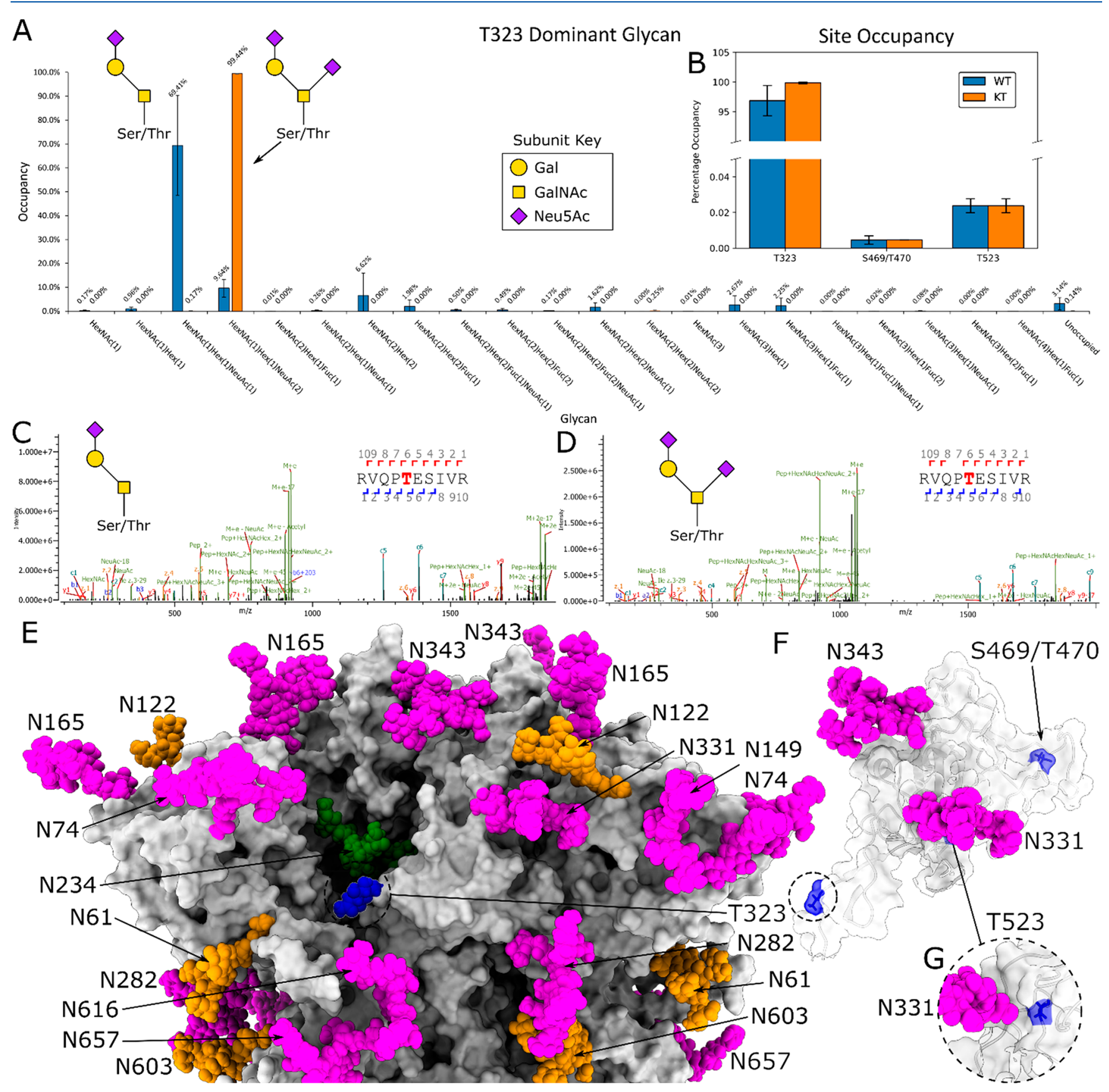

Figure 5. WT and KT O-glycan analysis of SARS-CoV-2 RBD: (A) Comparison of glycan composition at site T323 between WT and KT RBD, with the structures of mono- and disialylated core I HexNAc(1) $\mathrm{Hex}(1)$ glycans, with WT in blue and KT in orange. (B) Total site occupancy of Olinked glycans at T323, S469/T470, and T523 in RBD. (C, D) Example fragmentation spectra of T323 site mono- and disialylated core-I from (C) WT and (D) KT RBD. (E) S-protein trimer with oligomannose glycans shown in green, hybrid glycans shown in yellow, complex glycans shown in magenta, and O-glycan glycans shown in blue. (F) RBD construct with T323 and S469/T470 and (G) T523 residues in blue, using the full-length S-protein model presented in Allen et al. ${ }^{31}$ 
readily detectable O-linked glycan site on the ectodomains using the mixture of kifunensine treatment and $\mathrm{EThcD}$. This is in-line with studies on recombinant RBD reporting T323 as the predominate O-linked site. ${ }^{54-56} \mathrm{We}$ also show that kifunensine does not impact the occupancy of O-linked glycans, but may lead to dominance of capped, sialylated Olinked glycans. Further exploration of this effect is required, which we anticipate to be the subject of a future study. Using these techniques, we show that the difference in occupancy of T323 between trimeric S protein and monomeric RBD is likely due to placement of the O-glycan within a cleft on the trimeric protein, imposing steric hindrance on glycosylation machinery.

Our work also highlights that research describing high levels of O-linked glycan sites, which are glycosylated in the absence of proximal N-glycans, ${ }^{32,35,48}$ may be artifactual in nature. Although it could be envisaged that variations in cell lines and proteins may explain the discrepancies, many of these studies use HEK 293/293F and stabilized proteins. ${ }^{25,29,32,35,47,54,55}$ It should be noted that these experiments are performed on stabilized constructs in a recombinant setting, and the rules governing O-linked glycosylation of the $S$ protein in the context of natural infection may differ. Additionally, O-linked glycan enrichment may reveal further O-glycan sites that are present at very low levels. ${ }^{36,57}$

\section{ASSOCIATED CONTENT}

\section{SI Supporting Information}

The Supporting Information is available free of charge at https://pubs.acs.org/doi/10.1021/acs.analchem.1c01772.

Construct sequences, breakdown of N-link occupancy data, O-glycan fragmentation spectra, and O-glycan peptide tables (PDF)

\section{AUTHOR INFORMATION}

\section{Corresponding Author}

Max Crispin - School of Biological Sciences, University of Southampton, Southampton SO17 1BJ, U.K.; ㅈorcid.org/ 0000-0002-1072-2694; Email: max.crispin@soton.ac.uk

\section{Authors}

Charles F. S. Eldrid - School of Biological Sciences, University of Southampton, Southampton SO17 1BJ, U.K.; (1) orcid.org/0000-0001-5306-3644

Joel D. Allen - School of Biological Sciences, University of Southampton, Southampton SO17 1BJ, U.K.; 이이이.org/ 0000-0003-2547-968X

Maddy L. Newby - School of Biological Sciences, University of Southampton, Southampton SO17 1BJ, U.K.

Complete contact information is available at:

https://pubs.acs.org/10.1021/acs.analchem.1c01772

\section{Author Contributions}

${ }^{\#}$ C.E. and J.A. contributed equally to this work. C.E., J.A., M.N.: data collection; C.E., M.N.: sample preparation; C.E., J.A.: data analysis; C.E.: manuscript preparation; C.E., J.A., M.N., M.C.: manuscript revision; M.C.: study design. All authors read and approved the manuscript prior to submission.

\section{Funding}

Funded by the International AIDS Vaccine Initiative (IAVI) through Grant No. INV-008352/OPP1153692 and the IAVI Neutralizing Antibody Center through the Collaboration for AIDS Vaccine Discovery Grant No. OPP1196345/INV-
008813, both funded by the Bill and Melinda Gates Foundation. This work was also supported by the Bright Future Trust, and the University of Southampton Coronavirus Response Fund.

\section{Notes}

The authors declare no competing financial interest.

Data are available from the MassIVE database (https:// massive.ucsd.edu) with ID MSV000087897, doi:10.25345/ C5425B.

\section{ABBREVIATIONS}

ACE2 angiotension converting enzyme 2

FP fusion peptide

EThcD electron-transfer high-energy collision dissociation

HR1 heptapeptide repeat 1

HR2 heptapeptide repeat 2

KT kifunensine-treated

NTD N-terminal domain

PTM post-translational modification

RBD receptor binding domain

SARS-CoV-2 severe acute respiratory syndrome coronavirus-2 $S$ protein spike protein WT wild type

\section{REFERENCES}

(1) Huang, C.; Wang, Y.; Li, X.; Ren, L.; Zhao, J.; Hu, Y.; Zhang, L.; Fan, G.; Xu, J.; Gu, X.; Cheng, Z.; Yu, T.; Xia, J.; Wei, Y.; Wu, W.; Xie, X.; Yin, W.; Li, H.; Liu, M.; Xiao, Y.; Gao, H.; Guo, L.; Xie, J.; Wang, G.; Jiang, R.; Gao, Z.; Jin, Q.; Wang, J.; Cao, B. Lancet 2020, 395 (10223), 497-506.

(2) Yang, X.; Yu, Y.; Xu, J.; Shu, H.; Xia, J.; Liu, H.; Wu, Y.; Zhang, L.; Yu, Z.; Fang, M.; Yu, T.; Wang, Y.; Pan, S.; Zou, X.; Yuan, S.; Shang, Y. Lancet Respir. Med. 2020, 8 (5), 475-481.

(3) Lu, R.; Zhao, X.; Li, J.; Niu, P.; Yang, B.; Wu, H.; Wang, W.; Song, H.; Huang, B.; Zhu, N.; Bi, Y.; Ma, X.; Zhan, F.; Wang, L.; Hu, T.; Zhou, H.; Hu, Z.; Zhou, W.; Zhao, L.; Chen, J.; Meng, Y.; Wang, J.; Lin, Y.; Yuan, J.; Xie, Z.; Ma, J.; Liu, W. J.; Wang, D.; Xu, W.; Holmes, E. C.; Gao, G. F.; Wu, G.; Chen, W.; Shi, W.; Tan, W. Lancet 2020, 395 (10224), 565-574.

(4) Masters, P. S. The Molecular Biology of Coronaviruses. In Advances in Virus Research; Academic Press: Jan 1, 2006; pp 193-292. DOI: 10.1016/S0065-3527(06)66005-3.

(5) de Wit, E.; van Doremalen, N.; Falzarano, D.; Munster, V. J. Nat. Rev. Microbiol. 2016, 14, 523.

(6) Liang, Y.; Wang, M. L.; Chien, C. S.; Yarmishyn, A. A.; Yang, Y. P.; Lai, W. Y.; Luo, Y. H.; Lin, Y. T.; Chen, Y. J.; Chang, P. C.; Chiou, S. H. Front. Immunol. 2020, 11, 1022.

(7) Li, F. Annu. Rev. Virol. 2016, 3, 237-261.

(8) Letko, M.; Marzi, A.; Munster, V. Nat. Microbiol. 2020, 5 (4), $562-569$.

(9) Allen, J. D.; Watanabe, Y.; Chawla, H.; Newby, M. L.; Crispin, M. J. Mol. Biol. 2021, 433 (4), 166762.

(10) van Riel, D.; de Wit, E. Nat. Mater. 2020, 19, 810-812.

(11) Dong, Y.; Dai, T.; Wei, Y.; Zhang, L.; Zheng, M.; Zhou, F. Signal Transduction and Targeted Therapy 2020, 5, 237.

(12) Shields, A.; Faustini, S. E.; Perez-Toledo, M.; Jossi, S.; Aldera, E.; Allen, J. D.; Al-Taei, S.; Backhouse, C.; Bosworth, A.; Dunbar, L. A.; Ebanks, D.; Emmanuel, B.; Garvey, M.; Gray, J.; Kidd, I. M.; McGinnell, G.; McLoughlin, D. E.; Morley, G.; O'Neill, J.; Papakonstantinou, D.; Pickles, O.; Poxon, C.; Richter, M.; Walker, E. M.; Wanigasooriya, K.; Watanabe, Y.; Whalley, C.; Zielinska, A. E.; Crispin, M.; Wraith, D. C.; Beggs, A. D.; Cunningham, A. F.; Drayson, M. T.; Richter, A. G. Thorax 2020, 75 (12), 1089-1094.

(13) Cook, A. M.; Faustini, S. E.; Williams, L. J.; Cunningham, A. F.; Drayson, M. T.; Shields, A. M.; Kay, D.; Taylor, L.; Plant, T.; 
Huissoon, A.; Wallis, G.; Beck, S.; Jossi, S. E.; Perez-Toledo, M.; Newby, M. L.; Allen, J. D.; Crispin, M.; Harding, S.; Richter, A. G. J. Immunol. Methods 2021, 494, 113046.

(14) Li, W.; Hulswit, R. J. G.; Widjaja, I.; Raj, V. S.; McBride, R.; Peng, W.; Widagdo, W.; Tortorici, M. A.; van Dieren, B.; Lang, Y.; van Lent, J. W. M.; Paulson, J. C.; de Haan, C. A. M.; de Groot, R. J.; van Kuppeveld, F. J. M.; Haagmans, B. L.; Bosch, B.-J. Proc. Natl. Acad. Sci. U. S. A. 2017, 114 (40), E8508-E8517.

(15) Walls, A. C.; Xiong, X.; Park, Y. J.; Tortorici, M. A.; Snijder, J.; Quispe, J.; Cameroni, E.; Gopal, R.; Dai, M.; Lanzavecchia, A.; Zambon, M.; Rey, F. A.; Corti, D.; Veesler, D. Cell 2019, 176 (5), 1026-1039 e15.

(16) Tortorici, M. A.; Walls, A. C.; Lang, Y.; Wang, C.; Li, Z.; Koerhuis, D.; Boons, G.-J.; Bosch, B.-J.; Rey, F. A.; de Groot, R. J.; Veesler, D. Nat. Struct. Mol. Biol. 2019, 26 (6), 481-489.

(17) Hulswit, R. J. G.; Lang, Y.; Bakkers, M. J. G.; Li, W.; Li, Z.; Schouten, A.; Ophorst, B.; van Kuppeveld, F. J. M.; Boons, G.-J.; Bosch, B.-J.; Huizinga, E. G.; de Groot, R. J. Proc. Natl. Acad. Sci. U. S. A. 2019, 116 (7), 2681-2690.

(18) Baker, A. N.; Richards, S.-J.; Guy, C. S.; Congdon, T. R.; Hasan, M.; Zwetsloot, A. J.; Gallo, A.; Lewandowski, J. R.; Stansfeld, P. J.; Straube, A.; Walker, M.; Chessa, S.; Pergolizzi, G.; Dedola, S.; Field, R. A.; Gibson, M. I. ACS Cent. Sci. 2020, 6 (11), 2046-2052.

(19) Morniroli, D.; Giannì, M. L.; Consales, A.; Pietrasanta, C.; Mosca, F. Front. Immunol. 2020, 11, 1480.

(20) Engin, A. B.; Engin, E. D.; Engin, A. Environ. Toxicol. Pharmacol. 2020, 79, 103436.

(21) Watanabe, Y.; Berndsen, Z. T.; Raghwani, J.; Seabright, G. E.; Allen, J. D.; Pybus, O. G.; McLellan, J. S.; Wilson, I. A.; Bowden, T. A.; Ward, A. B.; Crispin, M. Nat. Commun. 2020, 11 (1), 2688.

(22) Yang, T. J.; Chang, Y. C.; Ko, T. P.; Draczkowski, P.; Chien, Y. C.; Chang, Y. C.; Wu, K. P.; Khoo, K. H.; Chang, H. W.; Hsu, S. T. D. Proc. Natl. Acad. Sci. U. S. A. 2020, 117 (3), 1438-1446.

(23) Liao, H.-Y.; Huang, H.-Y.; Chen, X.; Cheng, C.-W.; Wang, S.W.; Shahed-Al-Mahmud, M.; Chen, T.-H.; Lo, J. M.; Liu, Y.-M.; Ma, H.-H.; Chang, Y.-H.; Tsai, C.-Y.; Huang, P.-Y.; Chang, S.-Y.; Chao, T.-L.; Kao, H.-C.; Tsai, Y.-M.; Chen, Y.-H.; Chen, C.-Y.; Lee, K.-C.; Wu, C.-Y.; Jan, J.-T.; Lin, K.-I.; Cheng, T.-J. R.; Ma, C.; Wong, C.-H. Impact of Glycosylation on SARS-CoV-2 Infection and Broadly Protective Vaccine Design. bioRxiv, May 25, 2021, 2021.05.25.445523. DOI: 10.1101/2021.05.25.445523 (accessed 2021-07-30).

(24) Watanabe, Y.; Bowden, T. A.; Wilson, I. A.; Crispin, M. Biochim. Biophys. Acta, Gen. Subj. 2019, 1863 (10), 1480-1497.

(25) Watanabe, Y.; Allen, J. D.; Wrapp, D.; McLellan, J. S.; Crispin, M. Science (Washington, DC, U. S.) 2020, 369 (6501), No. 330.

(26) Kornfeld, R.; Kornfeld, S. Annu. Rev. Biochem. 1985, 54 (1), 631-664.

(27) Van den Steen, P.; Rudd, P. M.; Dwek, R. A.; Opdenakker, G. Crit. Rev. Biochem. Mol. Biol. 1998, 33, 151-208.

(28) Nishikawa, I.; Nakajima, Y.; Ito, M.; Fukuchi, S.; Homma, K.; Nishikawa, K. Int. J. Mol. Sci. 2010, 11 (12), 4991-5008.

(29) Zhao, P.; Praissman, J. L.; Grant, O. C.; Cai, Y.; Xiao, T.; Rosenbalm, K. E.; Aoki, K.; Kellman, B. P.; Bridger, R.; Barouch, D. H.; Brindley, M. A.; Lewis, N. E.; Tiemeyer, M.; Chen, B.; Woods, R. J.; Wells, L. Cell Host Microbe 2020, 28 (4), 586-601.

(30) Yao, H.; Song, Y.; Chen, Y.; Wu, N.; Xu, J.; Sun, C.; Zhang, J.; Weng, T.; Zhang, Z.; Wu, Z.; Cheng, L.; Shi, D.; Lu, X.; Lei, J.; Crispin, M.; Shi, Y.; Li, L.; Li, S. Cell 2020, 183 (3), 730-738.

(31) Allen, J. D.; Chawla, H.; Samsudin, F.; Zuzic, L.; Shivgan, A. T.; Watanabe, Y.; He, W.; Callaghan, S.; Song, G.; Yong, P.; Brouwer, P. J. M.; Song, Y.; Cai, Y.; Duyvesteyn, H. M. E.; Malinauskas, T.; Kint, J.; Pino, P.; Wurm, M. J.; Frank, M.; Chen, B.; Stuart, D. I.; Sanders, R. W.; Andrabi, R.; Burton, D. R.; Li, S.; Bond, P. J.; Crispin, M. Biochemistry 2021, 60 (27), 2153-2169.

(32) Zhang, Y.; Zhao, W.; Mao, Y.; Chen, Y.; Zhu, J.; Hu, L.; Gong, M.; Cheng, J.; Yang, H. Mucin-Type O-Glycosylation Landscapes of SARS-CoV-2 Spike Proteins. bioRxiv, July 30, 2020,
2020.07.29.227785. DOI: 10.1101/2020.07.29.227785 (accessed 2021-03-03).

(33) Zhao, P.; Praissman, J. L.; Grant, O. C.; Cai, Y.; Xiao, T.; Rosenbalm, K. E.; Aoki, K.; Kellman, B. P.; Bridger, R.; Barouch, D. H.; Brindley, M. A.; Lewis, N. E.; Tiemeyer, M.; Chen, B.; Woods, R. J.; Wells, L. Cell Host Microbe 2020, 28 (4), 586-601.

(34) Brun, J.; Vasiljevic, S.; Gangadharan, B.; Hensen, M.; Chandran, A. V.; Hill, M. L.; Kiappes, J. L.; Dwek, R. A.; Alonzi, D. S.; Struwe, W. B.; Zitzmann, N. ACS Cent. Sci. 2021, 7 (4), 586-593.

(35) Bagdonaite, I.; Thompson, A. J.; Wang, X.; Søgaard, M.; Fougeroux, C.; Frank, M.; Diedrich, J. K.; Yates, J. R.; Salanti, A.; Vakhrushev, S. Y.; Paulson, J. C.; Wandall, H. H. Viruses 2021, 13 (4), 551.

(36) Dong, X.; Chen, C.; Yan, J.; Zhang, X.; Li, X.; Liang, X. Anal. Chem. 2021, 93, 10444-10452.

(37) Zhang, S.; Go, E. P.; Ding, H.; Anang, S.; Kappes, J. C.; Desaire, H.; Sodroski, J.; Sodroski, J. G. Analysis of Glycosylation and Disulfide Bonding of Wild-Type SARS-CoV-2 Spike Glycoprotein. bioRxiv April 1, 2021, 2021.04.01.438120., DOI: 10.1101/ 2021.04.01.438120 (accessed 2021-04-12).

(38) Elbein, A. D.; Tropea, J. E.; Mitchell, M.; Kaushal, G. P. J. Biol. Chem. 1990, 265 (26), 15599-15605.

(39) Chang, V. T.; Crispin, M.; Aricescu, A. R.; Harvey, D. J.; Nettleship, J. E.; Fennelly, J. A.; Yu, C.; Boles, K. S.; Evans, E. J.; Stuart, D. I.; Dwek, R. A.; Jones, E. Y.; Owens, R. J.; Davis, S. J. Structure 2007, 15 (3), 267-273.

(40) Struwe, W. B.; Stuckmann, A.; Behrens, A.-J.; Pagel, K.; Crispin, M. ACS Chem. Biol. 2017, 12 (2), 357-361.

(41) Pallesen, J.; Wang, N.; Corbett, K. S.; Wrapp, D.; Kirchdoerfer, R. N.; Turner, H. L.; Cottrell, C. A.; Becker, M. M.; Wang, L.; Shi, W.; Kong, W. P.; Andres, E. L.; Kettenbach, A. N.; Denison, M. R.; Chappell, J. D.; Graham, B. S.; Ward, A. B.; McLellan, J. S. Proc. Natl. Acad. Sci. U. S. A. 2017, 114 (35), E7348-E7357.

(42) Wrapp, D.; Wang, N.; Corbett, K. S.; Goldsmith, J. A.; Hsieh, C.-L.; Abiona, O.; Graham, B. S.; McLellan, J. S. Science 2020, 367, 1260.

(43) Hsieh, C.-L.; Goldsmith, J. A.; Schaub, J. M.; DiVenere, A. M.; Kuo, H.-C.; Javanmardi, K.; Le, K. C.; Wrapp, D.; Lee, A. G.; Liu, Y.; Chou, C.-W.; Byrne, P. O.; Hjorth, C. K.; Johnson, N. V.; LudesMeyers, J.; Nguyen, A. W.; Park, J.; Wang, N.; Amengor, D.; Lavinder, J. J.; Ippolito, G. C.; Maynard, J. A.; Finkelstein, I. J.; McLellan, J. S. Science (Washington, DC, U. S.) 2020, 369 (6510), 1501-1505.

(44) Yu, Q.; Wang, B.; Chen, Z.; Urabe, G.; Glover, M. S.; Shi, X.; Guo, L. W.; Kent, K. C.; Li, L. J. Am. Soc. Mass Spectrom. 2017, 28 (9), 1751-1764.

(45) Reiding, K. R.; Bondt, A.; Franc, V.; Heck, A. J. R. TrAC, Trends Anal. Chem. 2018, 108, 260-268.

(46) Riley, N. M.; Malaker, S. A.; Driessen, M. D.; Bertozzi, C. R. J. Proteome Res. 2020, 19 (8), 3286-3301.

(47) Shajahan, A.; Supekar, N. T.; Gleinich, A. S.; Azadi, P. Glycobiology 2020, 30 (12), 981-988.

(48) Tian, W.; Li, D.; Zhang, N.; Bai, G.; Yuan, K.; Xiao, H.; Gao, F.; Chen, Y.; Wong, C. C. L.; Gao, G. F. Cell Res. 2021, 1-3.

(49) Chu, F. K. J. Biol. Chem. 1986, 261 (1), 172-177.

(50) Cao, L.; Diedrich, J. K.; Kulp, D. W.; Pauthner, M.; He, L.; Park, S.-K. R.; Sok, D.; Su, C. Y.; Delahunty, C. M.; Menis, S.; Andrabi, R.; Guenaga, J.; Georgeson, E.; Kubitz, M.; Adachi, Y.; Burton, D. R.; Schief, W. R.; Yates III, J. R.; Paulson, J. C. Nat. Commun. 2017, 8 (1), 14954.

(51) Casalino, L.; Gaieb, Z.; Goldsmith, J. A.; Hjorth, C. K.; Dommer, A. C.; Harbison, A. M.; Fogarty, C. A.; Barros, E. P.; Taylor, B. C.; Mclellan, J. S.; Fadda, E.; Amaro, R. E. ACS Cent. Sci. 2020, 6, 1722.

(52) Behrens, A.-J.; Harvey, D. J.; Milne, E.; Cupo, A.; Kumar, A.; Zitzmann, N.; Struwe, W. B.; Moore, J. P.; Crispin, M. J. Virol. 2017, 91 (2), e01894-16.

(53) Varki, A.; Cummings, R. D.; Esko, J. D.; Stanley, P.; Hart, G. W.; Aebi, M.; Darvill, A. G.; Kinoshita, T.; Packer, N. H.; Prestegard, 
J. H.; Schnaar, R. L.; Seeberger, P. H. Essentials of Glycobiology, 3rd ed.; Cold Spring Harbor Laboratory Press: 2017.

(54) Gstöttner, C.; Zhang, T.; Resemann, A.; Ruben, S.; Pengelley, S.; Suckau, D.; Welsink, T.; Wuhrer, M.; Domínguez-Vega, E. Anal. Chem. 2021, 93, 6839.

(55) Roberts, D. S.; Mann, M. W.; Melby, J. A.; Larson, E. J.; Zhu, Y.; Brasier, A. R.; Jin, S.; Ge, Y. J. Am. Chem. Soc. 2021, 143, 12014. (56) Antonopoulos, A.; Broome, S.; Sharov, V.; Ziegenfuss, C.; Easton, R. L.; Panico, M.; Dell, A.; Morris, H. R.; Haslam, S. M. Glycobiology 2021, 31 (3), 181-187.

(57) Huang, J.; Wang, D.; Shipman, R. D.; Zhu, Z.; Liu, Y.; Li, L. Anal. Bioanal. Chem. 2021, 1-9. 